\title{
PERANCANGAN SISTEM ADMINISTRASI BODY REPAIR MENGGUNAKAN JAVA PADA PT ASIA BERJAYA MOBILINDO
}

\author{
Binudi Probo Sidi ${ }^{1}$, Imam Sunoto ${ }^{2}$, Intan Mutia $^{3}$ \\ ${ }^{1,2,3}$ Teknik Informatika, Fakultas Teknik dan Ilmu Komputer, Universitas Indraprasta PGRI \\ Jl. Raya Tengah No.80, Gedong, Kec. Ps. Rebo, Kota Jakarta Timur, DKI Jakarta 13760 \\ $\underline{1 \text { mrbind87@gmail.com }}, \underline{2}$ raidersimam@gmail.com, ${ }^{3}$ As.syifaraa@gmail.com
}

\begin{abstract}
ABSTRAK
Sistem yang berjalan masih manual dan belum tertata dengan rapi. Tujuan penelitian ini untuk merancang sistem pengolahan administrasi perbaikan kendaraan body repair yang mudah digunakan agar dapat membantu pengguna terutamanya admin dalam mengoptimalkan kinerjanya di dalam laporan tanpa menyita waktu yang cukup lama. Metode penelitian yang digunakan adalah dengan metode Research and Development (R\&D) dimana metode penelitian ini digunakan untuk menghasilkan produk tertentu dan menguji keefektifan produk tersebut. Dalam pelaksanaan R\&D ini, penulis menggunakan pendekatan deskriptif untuk mengumpulkan informasi mengenai status gejala yang ada agar memperoleh data yang akurat. Hasil yang dicapai adalah meningkatnya kinerja admin dalam proses administrasi sudah lebih mudah dan cepat. Data-data penting sudah tersimpan rapi ke dalam sistem dengan basis data sehingga mempermudah pencarian ketika akan dibutuhkan.
\end{abstract}

Kata Kunci : Sistem, Administrasi, Body Repair.

\begin{abstract}
The system that runs is still manual and has not been arranged neatly. The purpose of this study is to design an easy-to-use body repair administrative processing system to help users, especially admins, optimize their performance in reports without taking a long time. The research method used is the Research and Development $(R \& D)$ method where this research method is used to produce certain products and test the effectiveness of these products. In the implementation of this $R \& D$, the author uses a descriptive approach to collect information about the status of existing symptoms in order to obtain accurate data. The result achieved is the increase in admin performance in the administrative process, which is easier and faster. Important data to be stored neatly into the system with a database so as to facilitate the search when it will be needed.
\end{abstract}

Key Word : System, Administration, Body Repair.

\section{PENDAHULUAN}

Industri otomotif di Indonesia saat ini terus mengalami perkembangan. Apalagi perkembangan kendaraan roda empat seperti mobil. mobil menjadi kendaraan yang memadati jalan raya. Membuat situasi dijalan raya tidak bisa ditebak, jumlah kecelakaan kendaraan ini sering kerap terjadi, entah itu kecelakaan berat ataupun ringan.

Namun hal ini justru menjadi peluang bagi bengkel pengecatan mobil atau kita lebih familiar dengan sebutan begkel Body repair. Bengkel tersebut melayani pengerjaan body kendaraan bermotor khususnya mobil yang telah mengalami kerusakan. Kerusakankerusakan yang mampu dibenahi oleh bengkel tersebut seperti body mobil yang penyok, lecet, custom body kit dan lain-lain. Salah satu perusahaan yang juga mengelola bengkel body repair adalah PT. Asia Berjaya Mobilindo (Mazda Cibubur). Sistem yang berjalan dalam
PT. Asia Berjaya Mobilindo masih menggunakan sistem manual dan sistem yang ada belum tertata dengan rapi, Jadi penulis akan mencoba menerapkan penggunaan sistem informasi yang terkomputerisasi yang dapat diaplikasikan pada pengolahan data administrasi bengkel berbasis Java Netbeans yang menggunakan database MySQL. Diperlukan suatu sistem informasi yang mampu mendukung pengolahan data administrasi dengan cepat dan tepat pada PT. Asia Berjaya Mobilindo. Penulis mencoba untuk membahas perancangan sistem administrasi bengkel dengan mengangkat judul Perancangan Sistem Administrasi Body repair menggunakan Java pada PT. Asia Berjaya Mobilindo.

Identifikasi masalahnya adalah pendataan kendaraan yang kurang efektif, pengolahan data yang masih kurang rapi, proses kerja yang lambat dan kurang efektif, Tidak adanya data 
file (invoice) yang sudah berlalu, Proses pencatatan data yang masih manual, Pembuatan laporang yang masih kurang lengkap.

Penelitian ini terbatas pada sistem informasi yang dirancang dan dibangun disesuaikan dengan kebutuhan proses bisnis pada PT Asia Berjaya Mobilindo, yaitu pencatatan identitas pelanggan dan kendaraan, Pencatatan keluhan pelanggan dan pekerjaan yang disetujui, Pembuatan estimasi pekerjaan dan spare part yang diganti, Pembuatan Faktur/Invoice ke Customer, Pembuatan Laporan. Laporan yang dihasilkan adalah laporan perbaikan bulanan. Laporan hasil penjualan bulanan. Perancangan sistem aplikasi pengolahan data menggunakan Bahasa Pemrograman Java Netbeans.

Penelitian ini bertujuan untuk Merancang suatu system aplikasi administrasi untuk perbaikan kendaraan bengkel yang mudah digunakan, efektif, dan efisien, Dapat mempermudah pembuatan laporan bengkel di PT Asia Berjaya Mobilindo, sehingga proses pekerjaan foreman di lapangan dapat optimal, tidak tersita waktu oleh pembuatan laporan bengkel.

Sistem Administrasi pada PT Asia Berjaya Mobilindo ini diharapkan sesuai dengan tujuan penelitian diatas, maka manfaat yang diharapkan dari penerapan sistem informasi ini yaitu agar dapat membantu instansi terkait terutama untuk admin dalam pengolahan data dan untuk mengevaluasi kekurangan pada bengkel terkait. Hasil dari penelitian ini dapat digunakan sebagai referensi dalam perancangan sistem terutama pada sistem Administrasi bengkel.

Adanya penelitian ini dapat menambah wawasan dan pengalaman dalam bidang Teknik Informatika serta sebagai salah satu syarat untuk meraih gelar Sarjana Strata Satu (S1) di Universitas Indraprasta PGRI Jakarta.

Menurut (Roger S. Pressman, 2012), "Perancangan sesungguhnya merupakan suatu aktivitas rekayasa perangkat lunak yang di maksud untuk membuat keputusan-keputusan utama, seringkali berisifat struktural".

Menurut (Satzinger Jackson Burd Staff., 2009) perancangan system adalah sekumpulan aktivitas yang menggambarkan secara rinci bagaimanasistem akan berjalan. Hal itu bertujuan untuk menghasilkan produkperangkat lunak yang sesuai dengan kebutuhan user.

Menurut (Kadir, 2014) bahwa "Sistem adalah sekumpulan elemen yang saling terkait atau terpadu yang dimaksudkan untuk mencapai suatu tujuan". Sedangkan menurut (Sutabri, 2012) "Sistem adalah suatu kumpulan atau himpunan dari suatu unsur, komponen, atau variabel yang terorganisasi, saling berinteraksi, saling tergantung satu sama lain dan terpadu".

Menurut (Hutahaean, 2015) Menjelaskan tentang pengertian pengolahan data, "Pengolahan data adalah serangkaian operasi atas informasi yang direncanakan guna mencapai tujuan atau hasil yang diinginkan". Sedangkan menurut (Sutarman, 2021), "Pengolahan data adalah proses perhitungan/transformasi data input menjadi informasi yang mudah dimengerti ataupun sesuai dengan yang diinginkan".

Menurut (Swastika et al., 2019), Administrasi mempunyai pengertian dalam arti sempit dan arti yang luas. Dalam arti sempit administrasi sering diartikan dengan kegiatan ketatausahaan. Tata usaha pada hakikatnya merupakan pekerjaan pengendalian informasi.Tata usaha juga sering diartikan sebagai kegiatan yang berkaitan dengan tulis menulis/mencatat, menggandakan, menyimpan, atau yang dikenal dengan clerical work.

Menurut (Silalahi, 2011) Administrasi dalam arti luas diartikan sebagai kerjasama. Istilah administrasi berhubungan dengan kegiatan kerjasama yang dilakukan manusia atau sekelompok orang sehingga tercapai tujuan yang diinginkan.

Menurut (Adisasmita, 2014) mengemukakan bahwa Transportasi adalah sarana penghubung atau yang menghubungkan antara daerah produksi dan pasar, atau dapat dikatakan mendekatkan daerah produksi dan pasar, atau seringkali dikatakan menjembatani produsen dengan konsumen. 


\section{METODE PENELITIAN}

Penelitian dilakukan di PT. Asia Berjaya Mobilindo untuk mengumpulkan data, lalu data-data tersebut penulis proses sehingga dapat dimanfaatkan dalam penelitian ini yang berlokasi di Jl. Raya Alternatif CibuburCileungsi KM.6, RT 002 RW 007, Desa Nagrak, Kecamatan Gunung Putri, Kabupaten Bogor, Jawa Barat, Indonesia 16967. Telp: 021-82487000.

Menurut (Sugiyono, 2013), metode penelitian pada dasarnya merupakan cara ilmiah untuk mendapatkan data dengan tujuan dan kegunaan tertentu. Metode penelitian yang digunakan peneliti dalam melakukan penelitian ini adalah metode Research and Development (R\&D). Metode pengumpulan data yang dilakukan oleh penulis untuk mendapatkan data-data serta informasi untuk mendukung penyempurnaan hasil dari penelitian ini adalah , Wawancara, dan Metode Kepustakaan.

Dalam mengembangkan sistem dibutuhkan desain sistem untuk menentukan bagaimana suatu sistem akan menyelesaikan apa yang harus diselesaikan. Metode pengembangan sistem yang digunakan adalah metode Waterfall, langkah-langkah pengembangan sistem dengan metode waterfall diantaranya Analisa Kebutuhan, Desain Sistem, Penulisan Kode Program, Pengujian Program, Penerapan Program dan Pemeliharaan.

\section{HASIL DAN PEMBAHASAN}

\section{Analisis Permasalahan}

Untuk saat ini system yang ada di Body \& Paint Cibubur ini masih konvensional dimana dalam pembuatan PKB, Estimasi, Faktur (Invoice) dan Laporan masih dilakukan secara manual (Microsoft Excel) dimana sangat riskan akan kesalahan, dan begitupun dengan monitoring pekerjaan yang dilakukan masih secara manual.

Dimulai dari bagian Service Advisor (SA) yag dimana pembuatan PKB masih manual (Microsoft Excel), dilanjutkan dengan estimasi dari bagian part juga masih manual lalu estimasi dikembalikan ke Service Advisor (SA), kemudian pelaporan ke asuransi kerusakan mobil dan estimasi by email, lalu dilanjutkan bagian foreman dimana pembuatan job control juga masih manual (Microsoft Excel), dan seterusnya sampai pada pembuatan invoice dan laporan

\section{Alternatif Penyelesaian Masalah}

Dengan adanya pekerjaaan yang dikerjakan manual maka dengan masalah tersebut kami mengusulkan untuk pembuatan sistem yang terkomputerisasi berbasis java. dimana dapat membatu dalam pembuatan Work Order (WO), Estimasi, Faktur (Invoice) lebih mudah, simple dan menpersingkat waktu. Selain itu dengan program ini juga dapat membantu menyimpan history dari pekerjaan yang sudah dilakukan, sehingga diharapkan dapat meminimalisir kesalahan dalam pelaporan.

\section{Rancangan Sistem yang Diusulkan}

1. Aturan Bisnis Sistem Yang Diusulkan

a. Customer datang dengan mobil yang akan di repair

b. Service Advisor (SA) menerima keluhan dari customer dan mencatatnya pada check sheet.

c. Service Advisor (SA) mendiagnosa kendaraan bersama customer dan memberikan penjelasan tentang diagnosa ke customer.

d. Service Advisor (SA) memberikan estimasi biaya, waktu dan pekerjaan.

e. Customer melakukan komfirmasi pekerjaan ke Service Advisor (SA)

f. Service Advisor (SA) membuat Work Order (WO).

g. Foreman memasukan mobil ke bengkel.

h. Mekanik melakukan perbaikan

i. Quality Control (QC) memantau pekerjaan perbaikan.

j. Foreman menyerahkan Mobil dan hasil laporan pekejaan ke Service Advisor

k. Service Advisor (SA) menyerahkan berkas dan lampiran pekerjaan ke Admin

1. Admin mencetak Faktur (Invoice)

m. Customer melakukan Pembayaran.

\section{Unified Modeling Language (UML) Sistem Yang Diusulkan \\ Use Case Diagram}

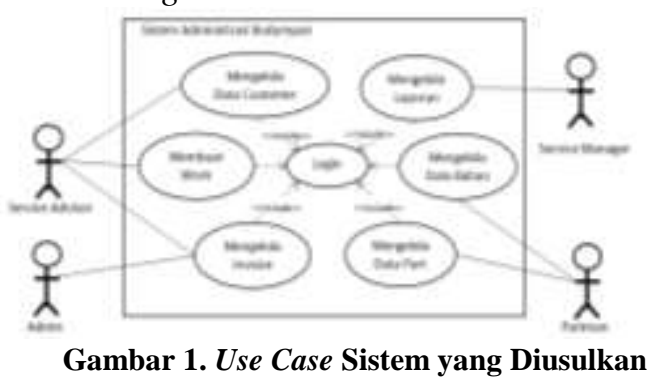


Rancangan Basis Data

Bentuk Normal Pertama (1NF)

Tabel 1. Bentuk Normal Pertama(1NF)

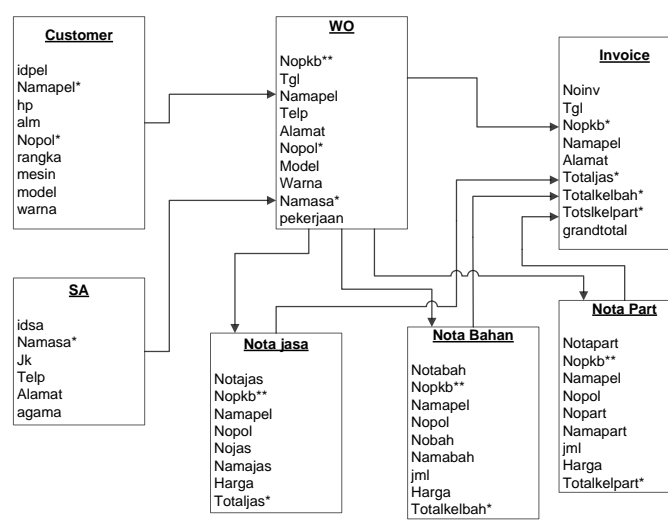

Tampilan Layar (Use Interface) Menu

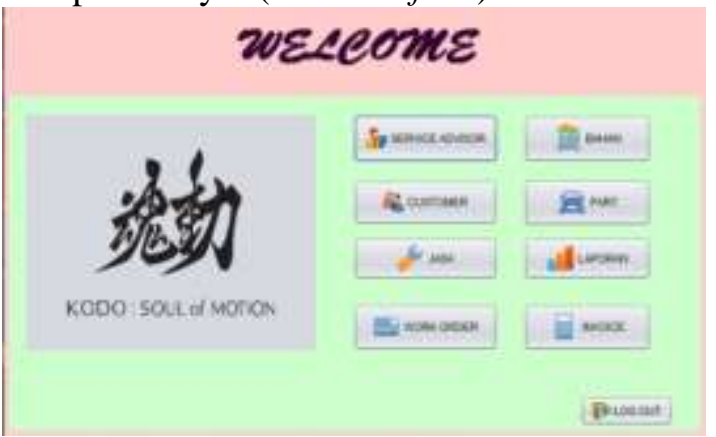

Gambar 2. Layar Menu

Pada gambar 2 ini terdapat menu utama dimana terdapat beberapa submenu diantaranya ada Service Advisor, Customer, Jasa, Bahan, Part, Work Order, Invoice, dan Laporan. Yang jika diklik dapat masuk ke form masing-masing sub menu.

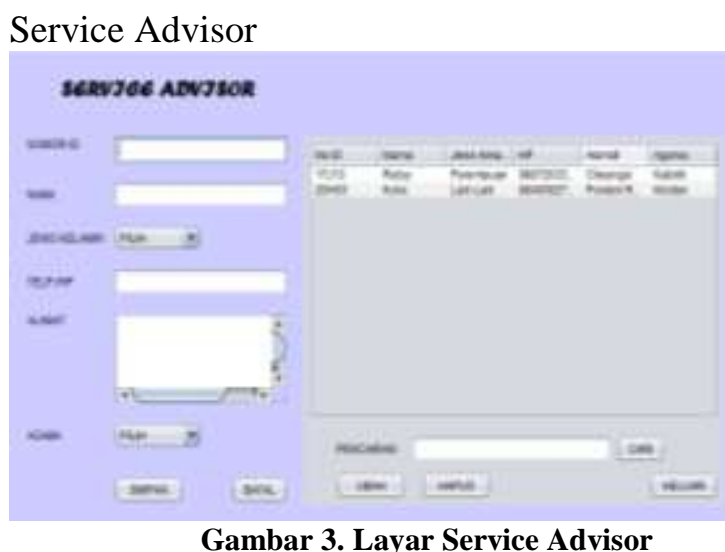

Pada gambar 3 ini terdapat sub menu Service Advisor dimana didalamnya terdapat kolomkolom untuk diisi data-data sesuai dengan nama data yang harus dimasukan pada kolom tersebut serta terdapat beberapa tombol yang memiliki fungsi masing-masing diantaranya Simpan untuk menyimpan data didalam database, Ubah untuk mengubah data yang telah tersimpan, Hapus untuk menghapus data yang telah tersimpan, dan Keluar untuk keluar dari sub menu dan kembali ke menu utama.

\section{Customer}

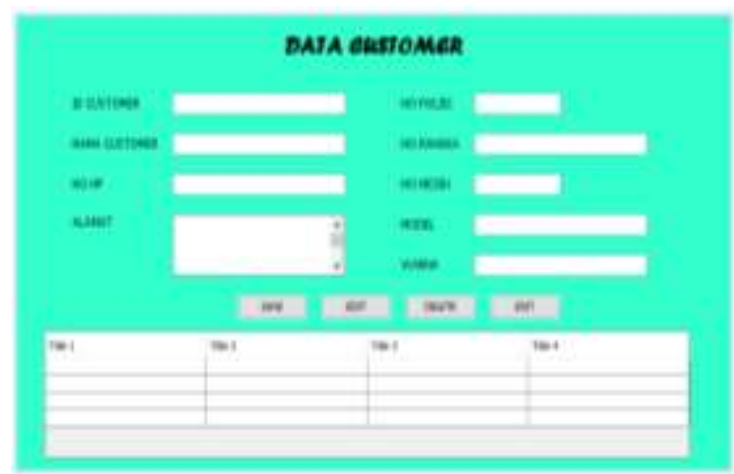

Gambar 4. Layar Customer

Pada gambar 4 ini terdapat sub menu Customer dimana didalamnya terdapat kolom-kolom untuk diisi data-data sesuai dengan nama data yang harus dimasukan pada kolom tersebut serta terdapat beberapa tombol yang memiliki fungsi masing-masing diantaranya Simpan untuk menyimpan data didalam database, Ubah untuk mengubah data yang telah tersimpan, Hapus untuk menghapus data yang telah tersimpan, dan Keluar untuk keluar dari sub menu dan kembali ke menu utama.

\section{Work Order (WO)}

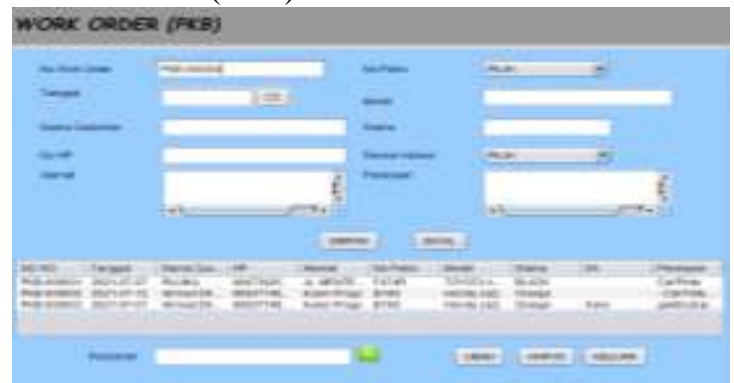

Gambar 5. Layar Work Order

Pada gambar 5 ini terdapat sub menu Work Order dimana didalamnya terdapat kolomkolom untuk diisi data-data sesuai dengan nama data yang harus dimasukan pada kolom tersebut serta terdapat beberapa tombol yang memiliki fungsi masing-masing diantaranya Simpan untuk menyimpan data didalam database, Ubah untuk mengubah data yang telah tersimpan, Hapus untuk menghapus data yang telah tersimpan, dan Keluar untuk keluar dari sub menu dan kembali ke menu utama. 
Invoice

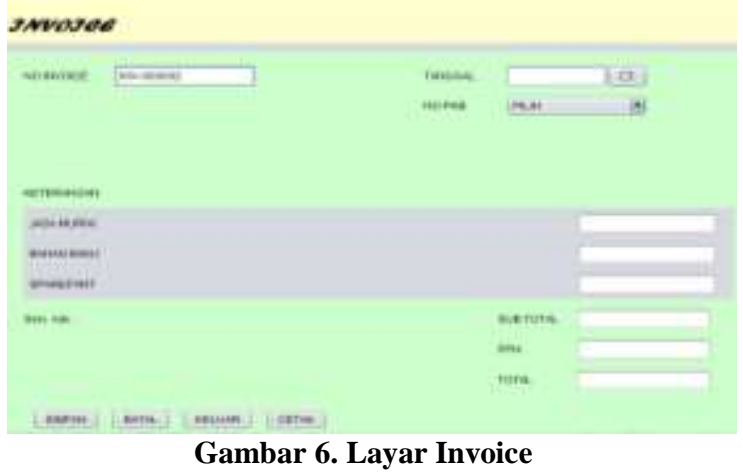

Pada gambar 6 ini terdapat sub menu Invoice dimana didalam menu ini hanya perlu memasukan tanggal dan nomor pkb untuk membuat semua kolom terisi karena sudah terkoneksi dengan database serta terdapat beberapa tombol yang memiliki fungsi masing-masing diantaranya Simpan untuk menyimpan data didalam database (invoice), Keluar untuk keluar dari sub menu dan kembali ke menu utama, dan cetak untuk mencetak invoice yang akan ditagihkan ke customer.

\section{Laporan}

Terdapat beberapa laporang pada aplikasi ini diantaranya adalah persediaan bahan, persediaan part, data customer, unit Entry, dan Penjualan (perbaikan body repair). Untuk lebih jelasnya bisa dilihat pada output laporan berikut ini :

\section{Laporan Persediaan Bahan}

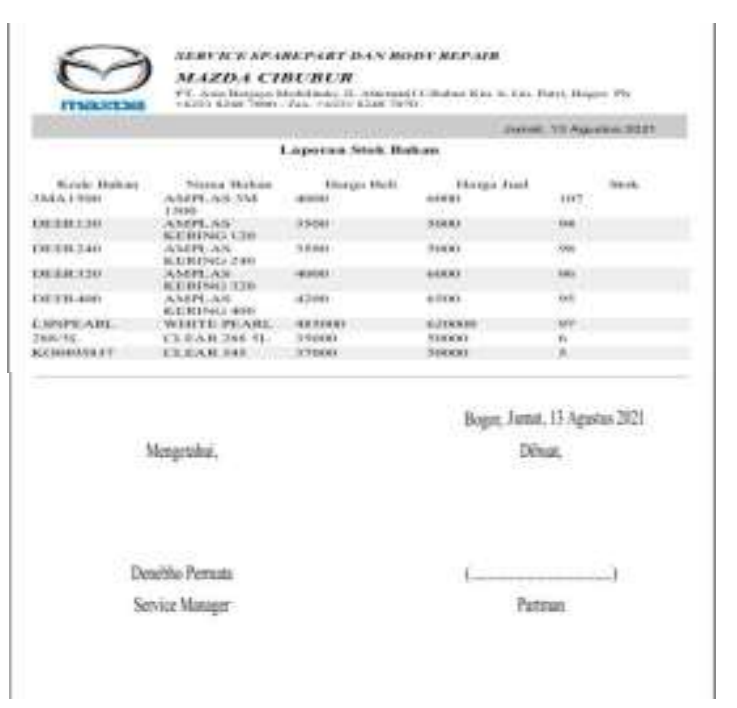

Gambar 7. Laporan Persediaan bahan

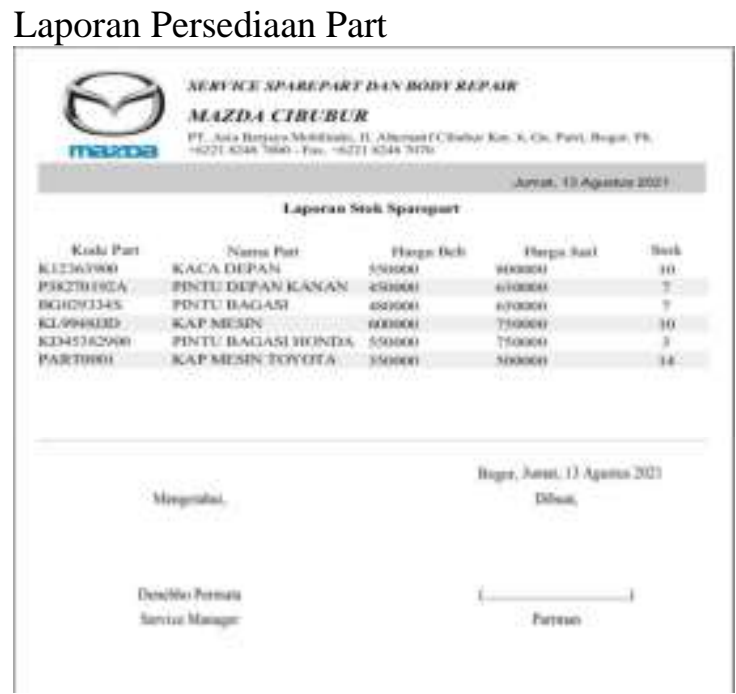

Gambar 8. Laporan Persediaan Part

\section{Laporan Data Customer}

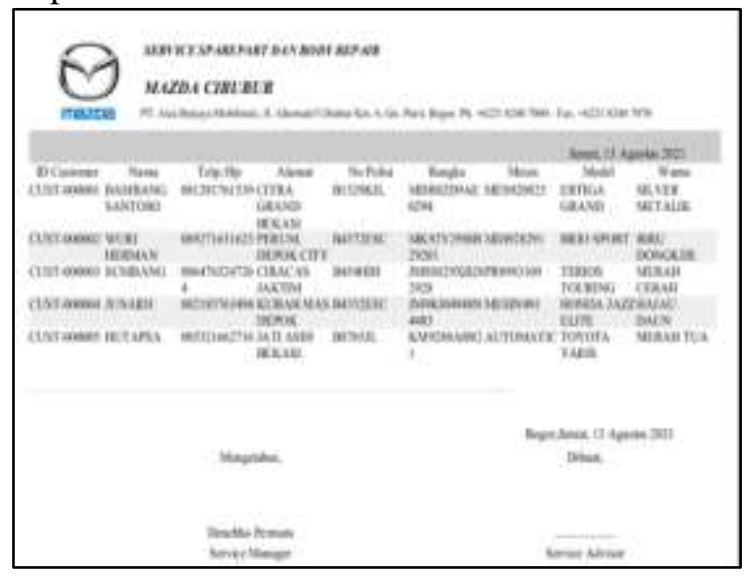

Gambar 9. Laporan Data Customer

\section{Laporan Unit Entry}

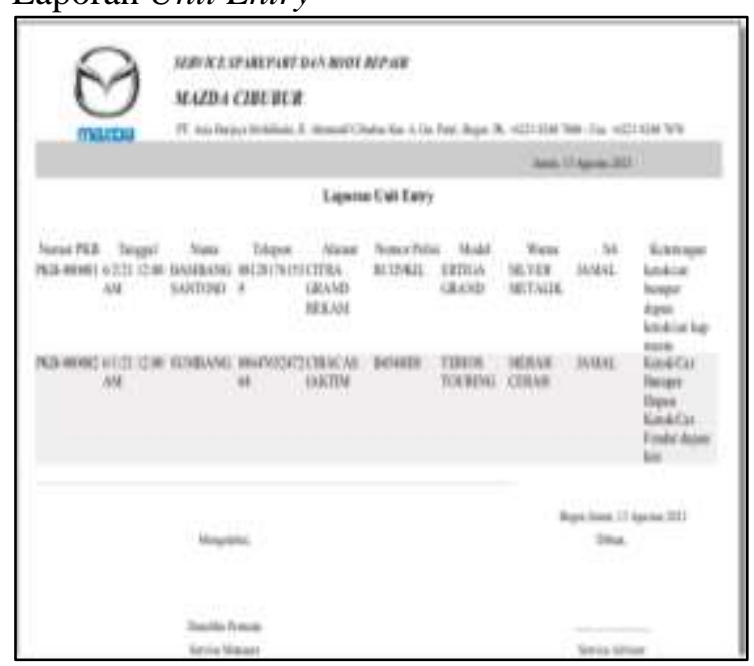

Gambar 10. Laporan Unit Entry 


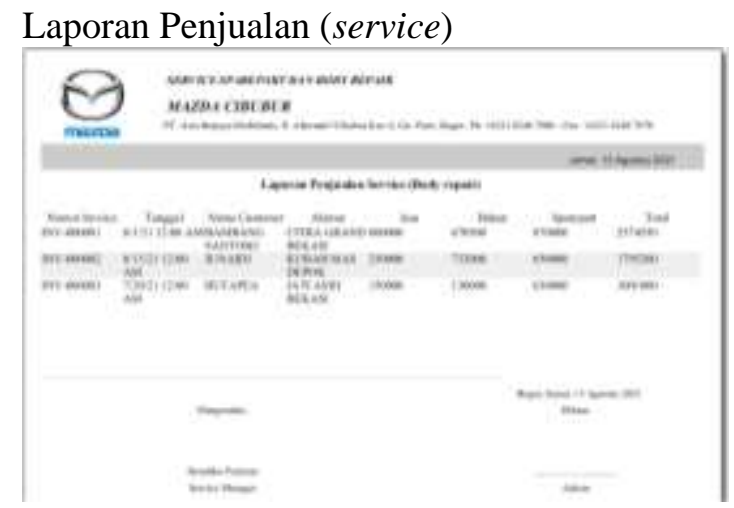

Gambar 11. Laporan Penjualan (Service)

Implementasi Pengujian Aplikasi

Pada tahap pengujian dilakukan dengan cara Blackbox Testng. Carapengujan dilakukan dengan menjalankan aplikasi administrasi \& monitoring Body \& Paint Mazda Cibubur dan melihat hasil output-nya apakah sesuai dengan hasil yang diharapkan. Kegiatan pengujian ini untuk memastikan adanya bug (kesalahan) atau tidak pada aplikasi sistem yang telah diuji, namun setidaknya dengan pengujian ini dapak meminimalisir bug (kesalahan) yang terdapat pada sistem.

\section{SIMPULAN DAN SARAN}

Berdasarkan pembahasan yang telah dijelaskan dapat diambil kesimpulan bahwa dengan diterapkannya Sistem Administrasi menggunakan Java pada PT. Asia Berjaya Mobilindo, perusahaan memiliki beberapa keuntungan, yaitu Proses dalam pembuatan Work Order yang lebih mudah untuk pembuatan dan pencetakannya, System sudah terkomputerisasi sehingga dapat lebih efektif dan dapat membantu mempermudah dalam proses administrasi yang dilakukan, History data tersimpan di database sehingga dapat menghindari kehilangan data lampau yang ingin di cari atau akan dipakai.

Adapun saran yang dapat penulis berikan untuk Sistem Administrasi menggunakan Java pada PT. Asia Berjaya Mobilindo adalah Sebelum menerapkn system ini diperlukan adanya pengarahan atau training mengenai menu yang terdapat di dalam system, Walaupun sudah terkomputerisasi perlu di perhatikan dalam ketelitian saat proses penginputan agar menghindari data salah atau eror, Untuk kedepannya sistem dapat lebih disempurnakan baik dari segi menu, fungsi ataupun dari segi tampilannya.

\section{DAFTAR PUSTAKA}

Adisasmita, S. A. (2014). Pengantar Perencanaan Transportasi. 262. https://www.pustaka.ut.ac.id/lib/pwkl41 03-perencanaan-transportasi/

Hutahaean, J. (2015). Konsep Dasar Sistem Informasi. Konsep Dasar Sistem Informasi, 1-36.

Kadir, A. (2014). Pengenalan sistem informasi edisi revisi. Yogyakarta: Andi, 2.No Title. Edisi Revisi, January. https://doi.org/10.13140/2.1.2637.6328

Roger S. Pressman. (2012). Rekayasa Perangkat Lunak Buku 1 Edisi 7. 260.

Satzinger Jackson Burd Staff. (2009). Systems Analysis and Design in a Changing World 5th (Fifth) - Chapter 2.

Silalahi, U. (2011). Asas-Asas Manajemen. Asas-Asas Manajemen, 1-23.

Sugiyono. (2013). Sugiyono Metode Penelitian Kuantitatif Kualitatif. Metode Penelitian Kuantitatif Kualitatif, 6.

Sutabri, T. (2012). Konsep Sistem Informasi. Jurnal Administrasi Pendidikan UPI, 3(1), 248.

Sutarman. (2021). Buku pengantar Teknologi Informasi (Issue May).

Swastika, W., Nur, A. W., \& Kelana, O. H. (2019). Monitoring Ruangan Untuk Deteksi Manusia Berbasis CNN Dengan Fitur Push Notification. Teknika, 8(2). https://doi.org/10.34148/teknika.v8i2.16 6 